\title{
Internal Design of Permanent-Magnet In-Wheel Motors for Battery-Powered Traction Applications
}

\author{
John Paul Spivey and Essam S. Hamdi \\ School of Science, Engineering \& Design \\ Teesside University \\ Middlesbrough, UK \\ p.spivey@tees.ac.uk
}

\begin{abstract}
This paper discusses design aspects of low-speed, permanent-magnet in-wheel motors suitable for low-power traction applications; such as fork-lift trucks and wheelchairs. It also investigates the force density dependence on current density and slot depth, with the aid of finite element (FE) modelling. Results are presented for practical slot dimensions and their application to specific designs is discussed.
\end{abstract}

Keywords-electric machines; electric drives; finite elements; force density; low speed.

\section{INTRODUCTION}

In a conventional radial flux-machine, the electric and magnetic loadings compete for the same space. Therefore, an increase in one would inevitably result in a decrease in the other [1]. In the quest for high torque density values, special designs employing axial and transverse-flux (e.g. claw-pole) have been investigated [2]-[7]. Such designs, however, are more intricate than the conventional (radial-flux) topology. They may require the use of soft magnetic composites (SMCs) adding to both material and manufacturing costs. Although such solutions have been considered for high-performance applications, their use in low-power traction applications can't be justified.

While in earlier work, [8], torque density values of radial, axial and transverse-flux machines are compared, the investigation was limited to one machine rating $(10 \mathrm{~kW}, 200$ $\mathrm{rev} / \mathrm{min}$ ). The work reported here investigates, with the aid of finite-element (FE) modelling, the force density dependence on current density and slot depth, for permanent-magnet radial-flux (PMRF), outer-rotor motors. The PMRF outer-rotor topology lends itself to the design of in-wheel motors. Low-speed inwheel motors need to be designed with a high number of poles. Additionally, as the motor size is limited by the diameter of the wheel, the number of slots-per-pole-per-phase (q) would be, in most cases, a fraction.

\section{A. Fractional-slot Winding}

These are a special form of windings in which the number of slots-per-pole-per-phase, $q$, is not an integer. For example given a 3 phase, 30 slot and 4 pole machine $q=5 / 2$. In practice, this would mean that, in one pole-pair, the phase group (or coilpitch) would be alternately 3 and 2 giving 5 slots per pole-pair per phase [9]. In such a case the winding pattern will be repeated every two poles. If there had been 27 slots instead of $30, q$ would have been equal to $9 / 4$ and the pattern would require four poles to complete. Therefore, in a fractional-slot winding, the denominator gives the number of poles required for a complete pattern and the numerator determines the number of slots that each phase takes up in this distance [9].

It is of course necessary for a three-phase balanced winding that the total number of slots is divisible by 3 , but it is not necessary that it should also be divisible by the number of poles. Fractional-slot winding permits the use of a standard lamination range for a wide variety of pole numbers [9].

Fractional-Slot Concentrated-Winding (FSCW) machines have been used in a wide range of applications, Electric and hybrid vehicles [10], home appliances [11], refrigeration compressors [12] and aircraft more electric engine (MEE) starter/generator [13], [14] are some examples. This popularity is due to the advantages that FSCW machines exhibit in comparison to Distributed Winding (DW) machines. In particular, FSCW yield shorter end-winding and a higher fill factor with respect to their counterpart. These features, especially when coupled to segmented stator structures, facilitate design of machines with improved efficiency and higher torque density. Furthermore, due to electrical, magnetic and thermal separation of the phases, the concentrated winding layout is associated to a higher fault tolerance. FSCW use also allows improvement of the constant power speed range in Surface Mounted Permanent Magnet (SMPM) machines [15], [16].

Direct-drive in-wheel motors used in traction applications must be designed with very high force densities to fulfil the peak torque requirement within the space envelope available. Likewise, low-speed direct-drive wind generators are another area that would require high force densities in achieving an optimised design suitable for transportation and mounting. In view of the low operating speeds, such applications inevitably lead to designs with a high number of poles, 28-poles is not untypical. However, machines with a small whole number of slots per-pole-per-phase $(q)$ have appreciable high-order harmonic emfs induced in the armature winding. If the winding is wound with a fractional number of slots-per-pole-per-phase, with a sufficiently well selected fractional coefficient, the separate elements of the winding (belonging to a given phase) would be under different poles (in different positions relative to the magnetic field). The displacement of these elements relative to the pole axis can then be chosen so that the fundamental emf will be only slightly reduced but the harmonics will diminish [9]. 


\section{B. Force Density}

Here, it is assumed that (in the absence of magnetic saturation), both the stator current loading and the flux density produced by the permanent magnets are sinusoidally distributed around the air-gap, with peak values $J_{p}(\mathrm{~A} / \mathrm{m})$ and $B_{p}(\mathrm{~T})$; respectively. The displacement between them is an angle $\lambda$, as depicted in Fig. 1.

In a non-salient machine, the magnetic flux produced by the stator does not contribute to the net force production (i.e the reluctance torque in negligible). The force density, $F_{a}$, can be determined by reformulating the conventional $F=B i l$ (where $l$ is the stack length) equation for an infinitesimal length of the air-gap circumference, integrating over one pole pair and dividing by the corresponding air-gap surface area. This yields:

$$
F_{a}=0.5 B_{p} J_{p} \cos \lambda
$$

The maximum force density is achieved when $\lambda$ equals zero. At this point the sinusoidal stator current loading and rotor flux density produced by the permanent magnets are in phase. As a result the load angle, $\delta$, between the stator and rotor $m m f$ 's will be $90^{\circ}$, the angle of maximum torque production.

The maximum allowable air-gap flux density, $B_{g}$, is limited by iron saturation. $B_{g}$ is proportional to the ratio of tooth-width to slot-pitch. Increasing the tooth-width, at the expense of a narrow slot, necessitates a reduction in current loading; resulting in no net increase in force density [1]. Therefore, the slot-width to tooth-width ratio can't be used to significantly increase the force density.

The peak current loading, $J_{p}$, can be expressed in terms of the $r m s$ value of the conductor current density, $J_{s}$, slot depth, $h_{s}$, and the slot-width to tooth-width ratio as follows [17]:

$$
J_{p}=\sqrt{2} J_{s} K_{C u}\left(h_{s}-2 w_{i}\right) \frac{w_{s}-2 w_{i}}{w_{s}+w_{t}}
$$

where $K_{C u}$ is the copper fill factor of the coil. Other parameters are as illustrated in Fig. 2.

Since the maximum allowable conductor current density, $J_{s}$, depends, largely, on the machine's cooling arrangement, Eq. (2) shows that the peak current loading (and force density) can be increased by increasing the slot depth, $h_{s}$. Of course, this will result in higher leakage flux and reactance [17].

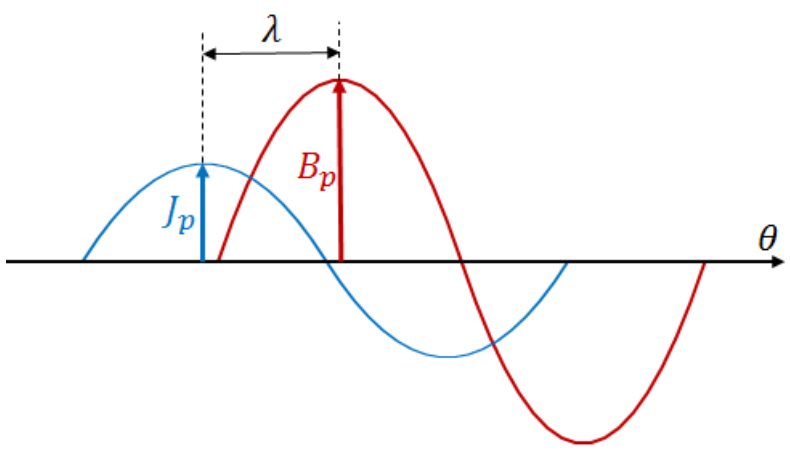

Fig. 1. Representation of the permanent-magnets flux density and stator current loading distributions along the air-gap.

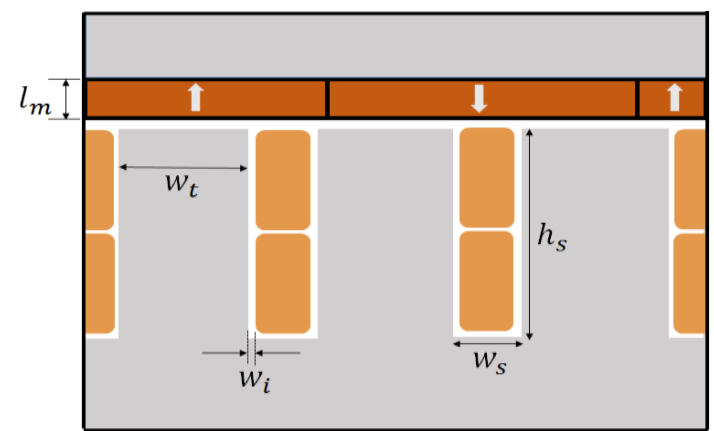

Fig. 2. Model parameters - surface magnet outer-rotor configuration.

\section{FORCE DENSITY COMPUTATION}

\section{A. Model Description}

In this investigation only the surface-magnet rotor configuration is considered. In order to maximise the achievable force density, the magnet pole arc is chosen as 180 electrical degrees. The model assumes rectangular open slots and the core material is represented by typical, non-linear, magnetisation characteristics. It may be noted that closed slots would yield approximately $10 \%$ greater force density in comparison to open slots [1]. The geometrical arrangement of the magnetic model used to investigate the force density in fractional-slot machines is shown in Fig. 3. This shows the typical field plots for a fractional-slot machine. As only machines with high pole number are considered here, stator curvature is neglected when considering a small section consisting of two poles.

In air-cooled machines, the maximum value of the electric loading that can be used, without exceeding the allowable temperature rise, varies with the slot depth. If the current density is kept constant, a deeper slot would increase the conductor cross-section area leading to higher copper losses. Also deeper slots result in losses being produced further away from the machine's outer frame (heat sink). Therefore, the conductor current density has to be reduced as the slot depth is increased. In this work, the peak electric loading values allowed for a class F insulation system, shown in Fig. 4, are used [1]. It is noted that, with increasing slot depth, the machine's electric loading increases while the current density is reduced. However, a relatively smaller increase can be achieved in slots more than $300 \mathrm{~mm}$ deep.
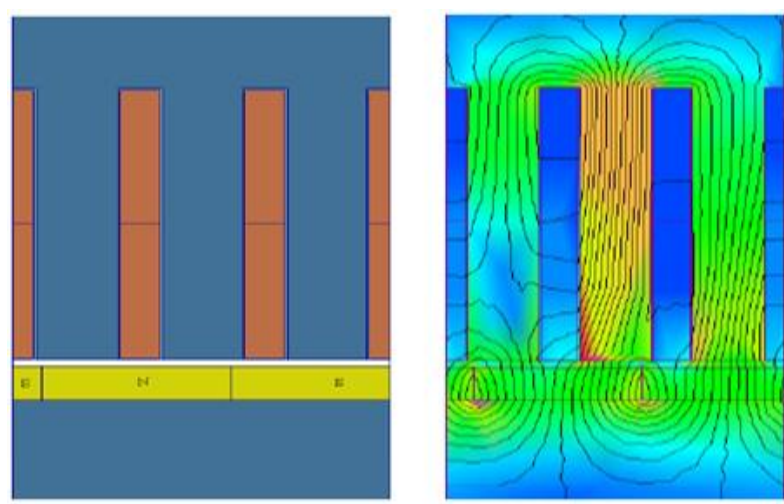

Fig. 3. Machine two-pole FE model. 


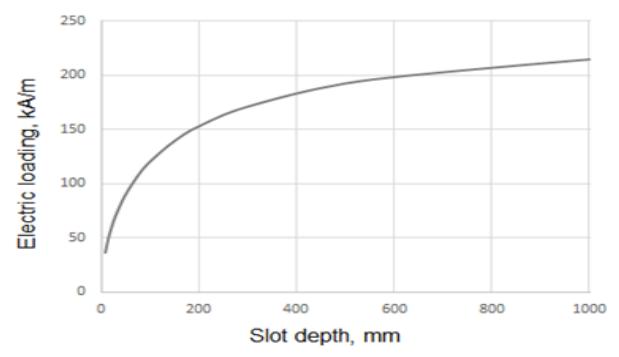

Fig. 4. Electric loading versus slot depth for a class F machine.

\section{B. Procedure}

As this work seeks to establish the maximum achievable force density values, a high-energy $\mathrm{NdFeB}$ magnet material $\left(\mathrm{B}_{\mathrm{r}}\right.$ 1.25 and $\mathrm{H}_{\mathrm{c}} 90 \mathrm{kA} / \mathrm{m}$ ) is assumed. The maximum allowable current density values for a class $\mathrm{F}$ insulation system [1] are used throughout the investigation.

For a given number of poles, the pole pitch $\left(\tau_{p}\right)$, slot width $\left(w_{s}\right)$, tooth width $\left(w_{t}\right)$, and magnet thickness $\left(l_{m}\right)$, all vary with slot depth $\left(h_{s}\right)$. It should be noted that the magnet thickness does not vary directly with slot depth. This is because the airgap length is kept constant and, therefore, the magnet operating point need only to be modified to provide additional $\mathrm{mmf}$ required to path the flux in deeper teeth. Increasing the slot depth in steps, while modifying other interrelated parameters, yields a number of machines; each represented by a row in Table 1.

Force density values were determined at a number of rotor positions for a machine having $h_{s}$ of $30 \mathrm{~mm}$ and $q=0.5$; assuming a sinusoidal stator current and constant rotor speed. This investigation revealed that the force density behaves in a cyclic manner with a period equal to the slot pitch. It may be noted that a similar behavior was observed in an earlier work concerning the case of one slot-per-pole-per-phase [18]. Based on this, in order to obtain meaningful results, the average of force density values determined at a number of rotor positions (ranging from 10 for slot pitch of $13.9 \mathrm{~mm}$, to 40 for a slot pitch of $71.15 \mathrm{~mm}$ ) is used. It should be noted that the peak force density does not occur when a north (or a south) pole is centered (0 degree), as shown in Fig. 3. Indeed, this corresponds to the minimum force density value.

TABLE I. MACHINE PARAMETERS.

\begin{tabular}{|c|c|c|c|c|c|c|}
\hline \multirow{2}{*}{$h_{s}, \mathrm{~mm}$} & \multirow{2}{*}{$w_{s}, \mathrm{~mm}$} & \multirow{2}{*}{$w_{t}, \mathrm{~mm}$} & \multicolumn{3}{|c|}{$\tau_{p}, \mathrm{~mm}$} & \multirow{2}{*}{$l_{m}, \mathrm{~mm}$} \\
\cline { 4 - 6 } & & & $q=0.375$ & $q=0.5$ & $q=0.75$ & \\
\hline 10 & 6.11 & 7.79 & 15.64 & 20.85 & 31.28 & 6.26 \\
\hline 15 & 6.22 & 8.42 & 16.46 & 21.95 & 32.93 & 6.59 \\
\hline 20 & 6.52 & 9.19 & 17.66 & 23.55 & 35.33 & 7.07 \\
\hline 30 & 7.15 & 10.67 & 20.06 & 26.75 & 40.13 & 8.02 \\
\hline 50 & 8.24 & 13.14 & 24.08 & 32.1 & 48.15 & 9.62 \\
\hline 75 & 9.29 & 15.60 & 27.98 & 37.3 & 55.95 & 11.20 \\
\hline 100 & 10.12 & 17.64 & 31.24 & 41.65 & 62.48 & 12.49 \\
\hline 150 & 11.43 & 21.04 & 36.53 & 48.7 & 73.05 & 14.61 \\
\hline 200 & 12.47 & 23.88 & 40.91 & 54.55 & 81.83 & 16.36 \\
\hline 300 & 14.14 & 28.63 & 48.11 & 64.15 & 96.23 & 19.25 \\
\hline 500 & 16.66 & 36.14 & 59.40 & 79.2 & 118.80 & 23.76 \\
\hline 750 & 19.10 & 43.63 & 70.58 & 94.1 & 141.15 & 28.23 \\
\hline 1000 & 21.16 & 49.99 & 80.06 & 106.75 & 160.13 & 32.02 \\
\hline
\end{tabular}

The electric loading (and current density) values given in Fig. 4 correspond to continuous operation. In traction applications, it is inevitable that the motor will be overloaded for short periods. Indeed, traction motors are required to withstand $100 \%$ overload for short (transient) periods. Therefore, here, average force density values are determined for the rated current as well as transient current expressed as multiple of the continuous rating.

\section{RESULTS}

\section{A. Force Density Variations with Slot Depth}

Force density variations with slot depths are determined for different current loadings, and used to identify the slot depth that maximises the force density. Fig. 5 shows the force density variation with slot depth for different current multiplication factors; corresponding to the slot and magnet dimensions of Tables 1.
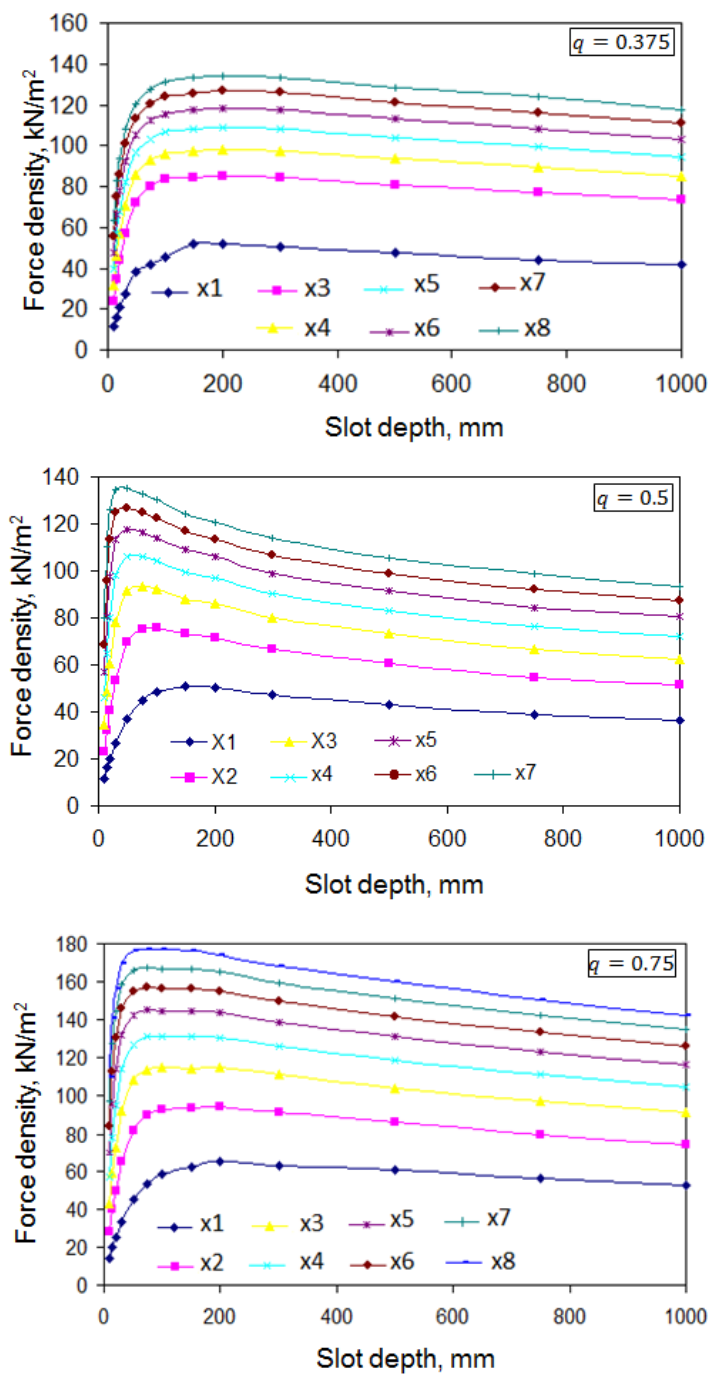

Fig. 5. Force density versus slot depth. 
With reference to Fig. 5, the effect of magnetic saturation is evident. For example, when $q=0.5$, the maximum achievable force density is about $50 \mathrm{kN} / \mathrm{m}^{2}$ at rated current loading. With a multiplication factor of $3(\mathrm{x} 3)$, the peak force density is only $70 \%$ higher. Similar effects are observed for other values of $q$. Also, for cases investigated here, it is seen that there is no performance improvement achievable from designs employing slots more than about $200 \mathrm{~mm}$.

To enable comparison with earlier work concerning designs employing one slot-per-pole-per-phase, the force density values with various current multiplication factors [18] is reproduced here as Fig. 6.

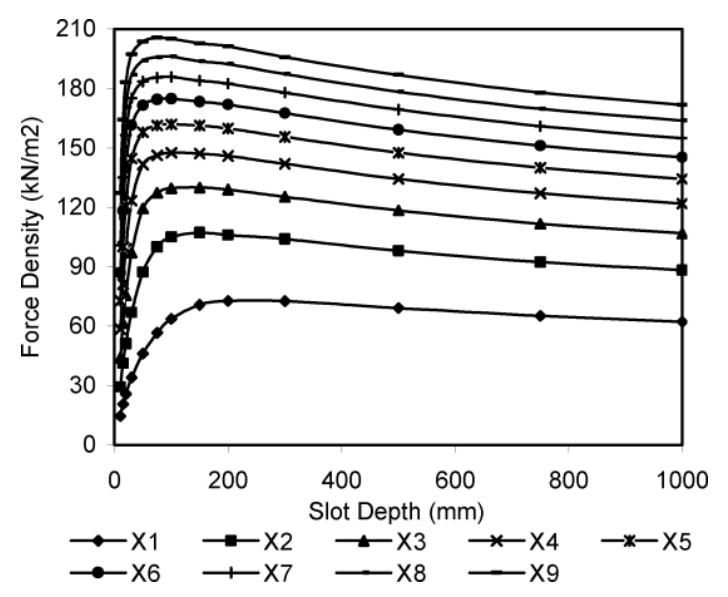

Fig. 6. Force density versus slot depth, $q=1$ [18]

Comparison between Figs. 5 and 6 shows that, for $q=0.5$ and 1, the achievable force densities are reduced by approximately, the ratio between the winding factors of the respective cases $(0.86$ and 1$)$. For a given air-gap diameter, this would necessitates a longer stack in order to produce the same force density values. However, the winding factor of a full-pitch integral-slot winding having more than one slot-per-pole-perphase is less than unity. Therefore, if such a winding were to be used, the percentage reduction would be less than $86 \%$.

A marginal reduction of force density values is observed for the case of $q=0.75$. The case of $q=0.375$ yields a significant reduction in achievable force density and this would require a substantial increase in stack length. This would be impractical in low-power traction application.

\section{B. Force Density Variation with Winding Current Density}

In order to present results in a form that can be readily utilised by a motor designer, the force density variation with slot depth are obtained for each of the machines depicted in Table 1. Data are produced for a range of current densities covering both air- and liquid-cooled windings.

By a way of an example, such data are presented here (Fig. 7) for a pole pitch of $20.85 \mathrm{~mm}, q=0.5$. This range of pole pitch values is suitable for use in designing motors that are restricted to a wheel diameter of 12 inches (or, $305 \mathrm{~mm}$ ). Fig. 7 shows that for a current density of $12 \mathrm{~A} / \mathrm{mm}^{2}$, a slot depth of about $30 \mathrm{~mm}$ would yield a force density value of $60 \mathrm{kN} / \mathrm{m}^{2}$. While such a current density value is greater than that recommended for air- cooled machines [1], applications employing 12-inch wheels (e.g. wheelchairs and golf carts) are designed for transient performance; the motor winding should handle such a current density values for short periods without overheating.

\section{CONCLUSIONS}

The maximum force density achievable for slot depths within the range of $10 \mathrm{~mm}$ to $1000 \mathrm{~mm}$ with different magnitudes of current loading is determined. The slot depths above which force density reduction would occur are identified. It is concluded that there are little or no advantages to be accrued by using slots more than $200 \mathrm{~mm}$ deep.

In order to achieve similar force density values, for a given air-gap diameter, a machine employing a fractional-slot winding with $q=0.5$ would need $15 \%$ longer stack than one with a full-pitch winding having one-slot-per-pole-phase. Use of windings with less than half a slot per-pole-per-phase should be avoided as this yields a significant reduction in the achievable force density values.

Variation of the achievable force density with winding current density (e.g. Fig. 7) is of a significant practical value. In this paper, a brief description of its application to a particular design is provided. Currently, the authors are developing a data bank, covering a range of pole-pitches, and incorporating it in a software intended for use as a design tool of battery-powered, low-power traction applications. The authors hope to report on this in near future.

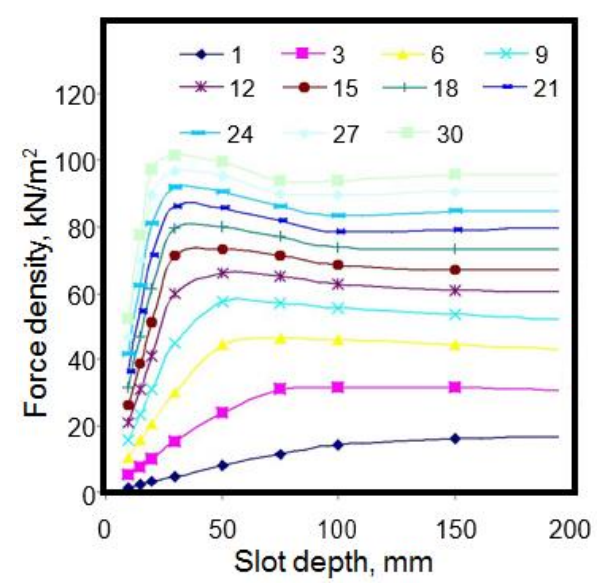

Fig. 7. Force density variation with winding current density $\left(\mathrm{A} / \mathrm{mm}^{2}\right)$, $\tau_{p}=20.85 \mathrm{~mm}$.

\section{REFERENCES}

[1] Hamdi, E. S., Design of Small Electrical Machines. John Wiley \& Sons, UK, 1994.

[2] J. Cros, P. Viarouge. "New Structures of Polyphase Claw-Pole Machines," IEEE Trans on Ind Appl, vol. 40, no. 1, pp. 113-120, 2004.

[3] S. T. Lundmark and E. S. Hamdi, "Construction, Operation and Internal Design of a Claw-Pole Servo Motor,” ELECTROMOTION, vol. 12, no. 2, pp. 127-132, 2006.

[4] M. Pinilla, "Performance improvement in a renewable energy direct drive permanent magnet machine by means of soft magnetic composite interpoles," IEEE Trans. Energy Convers., vol. 27, no. 2, pp. 440-448, Jun. 2012. 
[5] A. Boehm and I. Hahn, "Comparison of soft magnetic composites (SMCs) and electrical steel," in Proc. 2nd Int. Electr. Drives Prod. Conf. (EDPC), Oct. 2012, pp. 1-6.

[6] I. Boldea, L. N. Tutelea, L. Parsa, and D. Dorrell, "Automotive electric propulsion systems with reduced or no permanent magnets: An overview," IEEE Trans. Ind. Electron., vol. 61, no. 10, pp. 5696-5711, Oct. 2014.

[7] B. Zhang, T. Epskamp, M. Doppelbauer, and M. Gregor, “A comparison of the transverse, axial and radial flux PM synchronous motors for electric vehicle," in Proc. IEEE Int. Electr. Vehicle Conf. (IEVC), Dec. 2014, pp. $1-6$.

[8] J. Pippuri, A. Manninen, J. Keränen, and K. Tammi, "Torque density of radial, axial and transverse flux permanent magnet machine topologies," IEEE Trans. Magn., vol. 49, no. 5, pp. 2339-2342, May 2013.

[9] Hamdi, E. S., Permanent Magnets and Variable Reluctance Drive Systems. ETI Sweden, Chalmers Reproservice, 2003.

[10] P. B. Reddy, A. M. El-Refaie, K. K. Huh, J. K. Tangudu, and T. M. Jahns, "Comparison of Interior and Surface PM Machines Equipped with Fractional-Slot Concentrated Windings for Hybrid Traction Applications," IEEE Trans. Energy Conversion, vol. 27, no. 3, pp. 593602, 2012.

[11] S. Maekawa, K. Yuki, M. Matsushita, I. Nitta, Y. Hasegawa, T. Shiga, T. Hosoito, K. Nagai, H. Kubota, "Study of the Magnetization Method Suitable for Fractional-Slot Concentrated-Winding Variable Magnetomotive-Force Memory Motor," IEEE Trans. Power Electr, vol. 29, no. 9, pp. 2714-2720, 2014.
[12] K. Morimoto, Y. Kataoka, T. Uekawa. H. Kamiishida, "Noise Reduction of Swing Compressors with Concentrated Winding Motors," Proc. Of International Compressor Engineering Conference, Purdue, paper 1653 2004

[13] A. Boglietti, A. Cavagnino, A. Tenconi and S. Vaschetto, "The Safety Critical Electric Machines and Drives in the More Electric Aircraft: a Survey," Conf. Rec. IEEE-IECON'09, Porto, Portugal, pp. 2607-2614, 2009.

[14] R. Bojoi, A. Cavagnino, A. Miotto, A. Tenconi, and S. Vaschetto, "Radial Flux and Axial Flux PM Machines Analysis for More Electric Engine Aircraft Applications," IEEE-ECCE, Atlanta, Georgia, pp. 1672-1679, 2010.

[15] A. El-Refaye, "Fractional-Slot Concentrated-Windings Synchronous Permanent Magnet Machines: Opportunities and Challenges," IEEE Trans. Ind. Elect, vol. 57, no. 1, pp. 107-121, 2010.

[16] E. Fornasiero, L. Alberti, N. Bianchi, and S. Bolognani "Considerations on selecting fractional-slot nonoverlapped coil windings," IEEE Trans. on Ind. Applic., Vol.49, No.3, May/June 2013, pp.1316-1324.

[17] A. Grauers, P. Kasinathan, "Force density in low-speed PM Machines due to temperature and reactance," IEEE Trans. Energy Conversion, vol. 19, no. 3, pp. 518-525, 2004.

[18] A. Grauers and P. Kasinathan and E. S. Hamdi, "Force density limits in low-speed permanent-magnet Machines due to saturation," IEEE Trans. Energy Conversion, vol. 20, no. 1, pp. 37-44, 2005. 